\title{
Iso-conversional analysis of glass transition and crystallization in as-synthesis high yield of glassy $\mathrm{Se}_{98} \mathrm{Cd}_{2}$ nanorods
}

\author{
C. Dohare - N. Mehta
}

Received: 14 October 2011/ Accepted: 15 June 2012/Published online: 24 July 2012

(C) The Author(s) 2012. This article is published with open access at Springerlink.com

\begin{abstract}
In the present work, we have prepared high yield of glassy $\mathrm{Se}_{98} \mathrm{Cd}_{2}$ nanorods using melt-quench technique. The morphology and micro-structural analysis of as-prepared nanorods are characterized by SEM, XRD and EDX techniques. The glass transition and crystallization kinetics of glassy $\mathrm{Se}_{98} \mathrm{Cd}_{2}$ nanorods are studied at different heating rates $(5,10,15,20 \mathrm{~K} / \mathrm{min})$ using differential scanning calorimetric (DSC) technique. Four isoconversional methods [Kissinger-Akahira-Sunose (KAS), Flynn-Wall-Ozawa (FWO), Tang and Straink] were used to determine the various kinetic parameters (crystallization temperature $T_{\alpha \mathrm{c}}$, transition temperature $T_{\alpha \mathrm{g}}$, activation energy of crystallization $E_{\alpha c}$, activation energy of glass transition $E_{\alpha \mathrm{g}}$, order parameter $n$ ) of glass transition and crystallization process in non-isothermal mode. The monotonous decrease in activation energy $E_{\alpha}$ with the crystallization fraction $\alpha$ confirm the complex kinetic mechanism of the glassy $\mathrm{Se}_{98} \mathrm{Cd}_{2}$ nanorods.
\end{abstract}

Keywords Scanning electron microscope - Differential scanning calorimetry - Crystallization kinetics .

Glass transition $\cdot$ Chalcogenides $\cdot$ Nanorods

\section{Introduction}

Nano-objects and nanorods are important for the technological development in the field of solid state nanodevices (Geim and Novoselov 2007; Wallace 1947; Jorio et al.

C. Dohare · N. Mehta $(\bowtie)$

Department of Physics, Banaras Hindu University,

Varanasi 221 005, India

e-mail: dr_neeraj_mehta@yahoo.co.in
2008). Nano configuration based on different material compositions is important in the application of microdevices and nanodevices. The functionality of these materials is challenging for future nanotechnology (Sava and Simandan 2010). One-dimensional nanorods and nanowires have been the subject of great interest. In particular, the synthesis, nucleation and growth, diameter and length control of cadmium chalcogenide nanorods is one of the best examples (Hu et al. 1999; Jun et al. 2001; Felice et al. 2005). In chalcogenide materials, the interest is to find heterostructure and anisotropic nanorods made up of two or more distinct phases and containing large aspect ratio that could be assembled into functional material and devices (Purnima and Ruberu 2011). Heterostructures of cadmiumdecorated chalcogenide nanorods and nanoplates can be controllably fabricated by a microwave chemical technique (Mehta et al. 2010).

$\mathrm{Cd}-\mathrm{Se}$ and $\mathrm{Cd}-\mathrm{S}$ system are very important because of their possible efficiency as precursors for semiconducting layer fabrication. The film can also be obtained by laser deposition methods. Recently, it has been demonstrated that tuning of the diameter of CdSe nanorods in the $\mathrm{Cd}-\mathrm{Se}$ system with dimensions between 0 and 1 can be used more effectively for the variation of band gap, absorption and photoluminescence ( $\mathrm{Li}$ et al. 2001). Xerogels prepared from metal chalcogenide $\mathrm{CdSe}$ nanoparticles exhibit intermediate optical band edges ( $\mathrm{Yu}$ et al. 2009). A phase change memory nanotube of chalcogenide systems is reported by Jung et al. (2011).

Controlling the shape of nanostructures at the mesoscopic level is one of the most challenging issues faced by material scientists, since dimensionality plays a critical role in determining the physical properties of materials (Morales and Lieber 1998). One-dimensional (1D) nanostructures such as rods, wires, belts and tubes have become 
the focus of intensive research, owing to their unique applications in mesoscopic physics and fabrication of nanoscale devices. Several reports have been published recently on the production of chalcogenides at nanoscale (Khan et al. 2010a, b, 2011; Tripathi et al. 2009; Khan and Husain 2009). It is therefore an interesting topic of research. It is expected that once these chalcogenides are produced at nanoscale, they will show a dramatic change in their optical and electronic properties due to reduction of size. However, studies on nano-chalcogenides are still at the beginning and, accordingly, the overall features have not been discovered. These materials are potential candidates for optical memory applications. Hence, the investigation of kinetic parameters of glass transition and crystallization kinetics, specifically the variation of glass transition temperature, glass transition activation energy, crystallization temperature and crystallization activation energy with degree of conversion, is very important to find the suitability of this new nanostructured material for teststructure fabrication of non-volatile memories and phase change optical recording layers.

The kinetics of glass transition and crystallization is widely studied using differential scanning calorimetry (DSC) technique for obtaining important information regarding the transformation mechanism. For instance, different kinetic parameters (such as activation energy and reaction order) can be estimated using different methods. The methods commonly used for analyzing non-isothermal kinetics data are generally grouped into two categories: model-fitting and iso-conversional (model-free) methods. Model-fitting methods were widely used because of their ability to directly determine the kinetic triplet. These methods involve fitting different reaction models to experimental data, leading to a simultaneous determination of the kinetic parameters. In model-fitting methods, the kinetic parameters are assumed to be constant. On the other hand, iso-conversional (model-free) methods have become more popular because of their ability to determine the activation energy at the progressive extent of conversion $(\alpha)$ without assuming any reaction model (Abu-Sehly 2009).

Keeping in view the technological importance of selenium and cadmium, it is therefore interesting to investigate the crystallization and glass transition kinetics in Se-rich $\mathrm{Se}-\mathrm{Cd}$ alloy system at nanoscale. Hence, we have focused our research in this new direction. We have prepared high yield of glassy $\mathrm{Se}_{98} \mathrm{Cd}_{2}$ nanorods using simple, well-known and cost-effective method of melt-quench technique. This method avoids the need of exotic chemicals, high temperatures and high pressures and offers the simplest approach. The present paper reports the results of structural analysis and calorimetric measurements on high yield of glassy $\mathrm{Se}_{98} \mathrm{Cd}_{2}$ nanorods.

\section{Materials and methods}

A glassy alloy of $\mathrm{Se}_{98} \mathrm{Cd}_{2}$ was prepared by the quenching technique. The exact proportions of high purity $(99.999 \%)$ elements, in accordance with their atomic percentages, were weighed using an electronic balance (LIBROR, AEG-120) with the least count of $10^{-4} \mathrm{~g}$. The materials were then sealed in evacuated $\left(\sim 10^{-6}\right.$ Torr) quartz ampoules (length $\sim 5 \mathrm{~cm}$ and internal diameter $\sim 8 \mathrm{~mm}$ ). Each ampoule was kept inside the furnace at $1,000{ }^{\circ} \mathrm{C}$ (where the temperature was raised at a rate of $3-4{ }^{\circ} \mathrm{C} / \mathrm{min}$ ). During heating, all the ampoules were constantly rocked, by rotating a ceramic rod to which the ampoules were tucked away in the furnace. This was done to obtain a homogeneous glassy alloy.

After rocking for about $12 \mathrm{~h}$, the obtained melts were cooled rapidly by removing the ampoules from the furnace and dropping into ice-cooled water rapidly. The ingots of the samples were then taken out by breaking the quartz ampoules. The surface morphology and chemical composition of synthesized nanorods were characterized by using SEM, XRD and EDS techniques. The XRD pattern of the annealed sample was obtained from X-ray diffractometer using $\mathrm{CuK}_{\alpha}$ radiation $\left(\lambda=1.5405 \mathrm{~A}^{\circ}\right)$. The $\mathrm{X}$-ray tube voltage and current were $30 \mathrm{kV}$ and $20 \mathrm{~mA}$, respectively. The scan range was $5-80^{\circ}(2 \theta)$ and the scan speed was $1 \%$ min.

The glass, thus prepared, was ground to make a fine powder for DSC studies; $10-20 \mathrm{mg}$ of the powder was heated at a constant rate and the changes in heat flow with respect to an empty reference pan were measured. The thermal behavior was investigated using differential scanning calorimeter. The temperature precision of this equipment is $\pm 0.1 \mathrm{~K}$ with an average standard error of about $\pm 1 \mathrm{~K}$ in the measured values (glass transition and crystallization temperatures). Measurements were made under almost identical conditions at four different heating rates, $5,10,15$ and $20^{\circ} \mathrm{C} / \mathrm{min}$, so that a comparison of various kinetic parameters of glass transition and crystallization could be made in the binary $\mathrm{Se}_{98} \mathrm{Cd}_{2}$ alloy.

\section{Theoretical basis for iso-conversional analysis of glass transition and crystallization kinetics}

Iso-conversional methods have been known for many years (Friedman 1964; Kissinger 1956, 1957; Akahira and Sunose 1971; Ozawa 1965, 1971; Flynn and Wall 1966). These methods yield the values of effective activation energy as a function of conversion. Nevertheless, except for the pioneering work of Flynn and Wall (1966), the obtained variation of the activation energy on conversion was considered more as a problem than as a powerful source of information that could be used for elucidation of 
the kinetic mechanism of the overall process under study. As compared to the authentic iso-conversional methods (Friedman 1964; Kissinger 1956, 1957; Akahira and Sunose 1971; Ozawa 1965, 1971; Flynn and Wall 1966), the general non-isothermal methods have a disadvantage of producing a single value of the activation energy for the whole process. As a result, activation energy variations that may accompany complex (e.g., multi-step) kinetics may not be revealed by such methods.

Recently, many co-workers have shown how a complete iso-conversional kinetic analysis can be performed using the dependence of the activation energy on conversion, by thermo analytical data like differential scanning calorimetry (DSC) (Kotkata and Mansour 2010; Abu-Sehly 2011). Model-free iso-conversional methods are among the most reliable for determining activation energies of thermally stimulated complex processes. Recently, these methods have been widely used to study the kinetics of chemical or physical processes, allowing to draw significant conclusions on the mechanisms of various chemical reactions, cross-linking, renewable thermosets, polymer crystallization, glass transition kinetics, thermal and thermo-oxidative degradation, protein denaturation and glass aging (Vyazovkin 1996; Vyazovkin and Sbirrazzuoli 1996, 2006; Vyazovkin and Sbirrazzuoli 2003). Data simulations are also very necessary for these methods for large-scale or industrial purposes, because these simulations do not need any assumptions on the reaction mechanism. It has been experimentally demonstrated that the model-free equations give rise to reliable predictions, whereas the substitution of kinetic triplets, obtained from single heating rate run, yields fundamentally erroneous predictions.

The kinetics of crystallization in amorphous material can be described by the following rate equation (Vyazovkin 2000):

$\frac{\mathrm{d} \alpha}{\mathrm{d} t}=A \exp \left(-\frac{E}{R T}\right) f(\alpha)$,

where $f(\alpha)$ is the reaction model. Under non-isothermal condition with a constant heating rate $\beta=\frac{\mathrm{d} T}{\mathrm{~d} t}$, Eq. (1) may be written as:

$\frac{\mathrm{d} \alpha}{\mathrm{d} T}=\frac{\mathrm{d} \alpha}{\mathrm{d} t}\left(\frac{1}{\beta}\right)=\frac{A}{\beta} \exp \left(-\frac{E}{R T}\right) f(\alpha)$.

The integral form of the reaction model can be obtained by integrating Eq. (2) as:

$g(\alpha)=\int_{0}^{\alpha} \frac{\mathrm{d} \alpha}{f(\alpha)}=\frac{A}{\beta} \int_{0}^{t} \exp \left(-\frac{E}{R T}\right) \mathrm{d} T=\frac{A}{\beta} I(E, T)$.

Using an advanced iso-conversional method, $n$ experiments are carried out at different heating rates and the effective activation energy can be determined at any particular value of $\alpha$, where the integral $I I(E, T)$ is given by

$I(E, T)=\int_{0}^{t} \exp \left(-\frac{E}{R T}\right) \mathrm{d} t$

Kissinger-Akahira-Sunose (KAS) method

Iso-conversion methods require the determination of the temperature $T_{\alpha i}$ at which a fixed fraction of the total amount is transformed. In (KAS) method, the relation between the temperature, $T_{\alpha i}$ and heating rate, $\beta_{i}$ is given by (Kissinger 1956, 1957; Akahira and Sunose 1971):

$\ln \left(\frac{\beta_{i}}{T_{\alpha i}^{2}}\right)=-\frac{E_{\alpha}}{R T_{\alpha i}}+$ constant.

The subscript $i$ denotes different heating rates. For each degree of conversion, corresponding $T_{\alpha i}$ and heating rate are used.

Flynn-Wall-Ozawa (FWO) method

Flynn-Wall-Ozawa method (Ozawa 1965, 1971; Flynn and Wall 1966) has been used for the determination of nonisothermal analysis of crystallization in which the temperature integral in Eq. (3) is simplified by using the Doyle's approximation (Doyle 1961, 1965) and the relation is estimated as follows:

$\ln \beta_{i}=-1.052 \frac{E_{\alpha}}{R T_{\alpha i}}+$ constant.

Tang method

Temperature integral relation has been suggested by Tang and given as (Wanjun and Donghua 2005):

$\ln \left(\frac{\beta_{i}}{R T_{\alpha, i}^{1.895}}\right)=-1.00145\left(\frac{E_{\alpha}}{R T_{\alpha i}}\right)+$ constant.

Straink method

The method proposed by Straink is given as (Starink 2003, 2007):

$\ln \left(\frac{\beta_{i}}{T_{\alpha i}^{1.92}}\right)=-1.0008\left(\frac{E_{\alpha}}{R T_{\alpha i}}\right)+$ constant.

\section{Results and discussion}

The crystalline phases are identified by annealing the as-prepared sample near the crystallization temperature for $1 \mathrm{~h}$. The XRD pattern of the annealed sample of $\mathrm{Se}_{98} \mathrm{Cd}_{2}$ is shown in Fig. 1. The XRD pattern clearly shows the 
presence of Se and $\mathrm{Cd}$ elements. The peaks are not very sharp, which show the amorphous nature of the sample. The peaks were identified in the JCPDS profile. This profile confirms the presence of Se and $\mathrm{Cd}$ and CdSe hexagonal phases in the as-synthesis glassy alloy. Experimental and calculated values of inter-planar spacing $d$ and

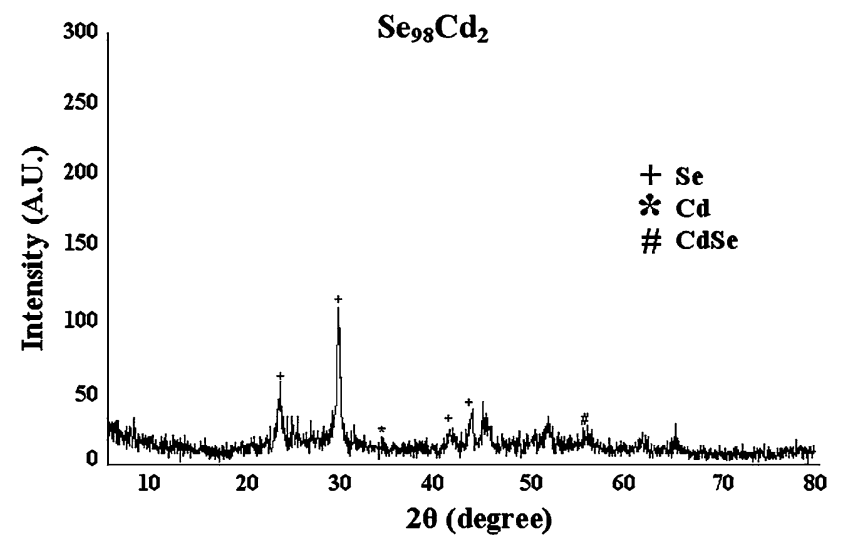

Fig. 1 XRD pattern of glassy $\mathrm{Se}_{98} \mathrm{Cd}_{2}$ nanorods annealed for $1 \mathrm{~h}$ near crystallization temperature

Table 1 Theoretical and experimental values of inter-planar spacing $d$ and Miller indices (hkl) in $\mathrm{Se}_{98} \mathrm{Cd}_{2}$ nanorods for different planes

\begin{tabular}{lllll}
\hline Crystalline phase & $2 \theta$ (degree) & \multicolumn{2}{l}{$d\left(\mathrm{~A}^{\circ}\right)$ values } & (hkl) \\
\cline { 3 - 4 } & & Experimental & Theoretical & \\
\hline $\mathrm{Se}$ & 23.025 & 3.859 & 3.781 & 100 \\
$\mathrm{Se}$ & 29.205 & 3.055 & 3.006 & 101 \\
$\mathrm{Se}$ & 41.055 & 2.196 & 2.183 & 110 \\
$\mathrm{Se}$ & 43.270 & 2.089 & 2.569 & 102 \\
$\mathrm{Cd}$ & 33.125 & 2.702 & 2.575 & 100 \\
$\mathrm{CdSe}$ & 55.445 & 1.656 & 1.644 & 202 \\
\hline
\end{tabular}

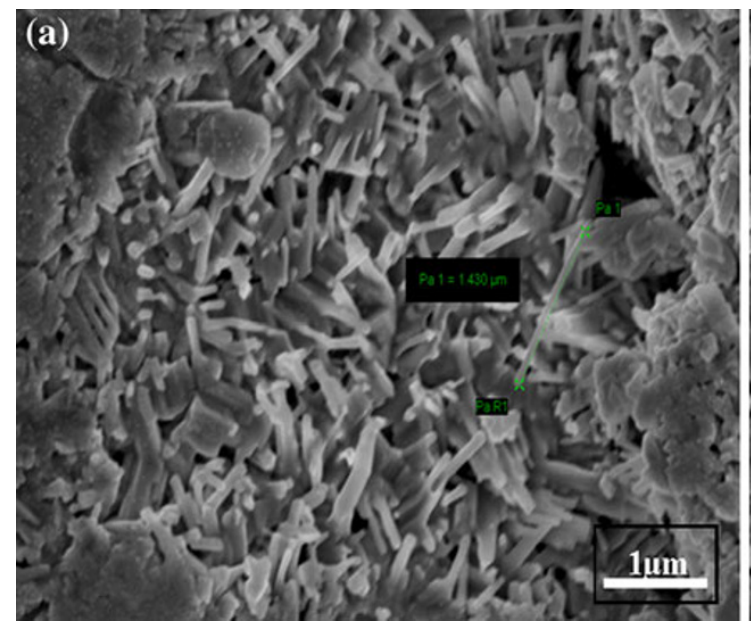

corresponding (hkl) values at particular different angles are given in Table 1 for the observed phases. The average particle sizes of different phases present in glassy $\mathrm{Se}_{9} 8 \mathrm{Cd}_{2}$ nanorods system are calculated with the help of Sherror formula. The aggregate particle size of $\mathrm{Se}, \mathrm{Cd}$ and $\mathrm{CdSe}$ phases is $20.3,36.5$ and $94 \mathrm{~nm}$, respectively.

Surface morphology is characterized by scanning electron microscope (SEM), which shows the nanorods formation in chalcogenide $\mathrm{Se}_{98} \mathrm{Cd}_{2}$ system. The SEM photographs are shown in Fig. 2a, b. These figures clearly show that nanorods of different lengths and diameters are embedded in the amorphous matrix. The average length of nanorods is nearly $1 \mu \mathrm{m}$ and the average diameter is $130 \mathrm{~nm}$. Energy dispersion spectrum (EDS) of glassy $\mathrm{Se}-\mathrm{Cd}$ nanorods is shown in Fig. 3. This figure shows the presence of Se and Cd element in as-synthesized $\mathrm{Se}_{98} \mathrm{Cd}_{2}$ alloy.

The glass transition and crystallization kinetics are generally well characterized from the data of DSC experiment at different heating rates. Figure 4 shows the typical DSC scans at heating rates of 5,10,15 and $20 \mathrm{~K} / \mathrm{min}$ for glassy $\mathrm{Se}_{98} \mathrm{Cd}_{2}$ alloy. Each DSC scan shows a well-defined endothermic and exothermic peak at the glass transition temperature $T_{\mathrm{g}}$ and crystallization temperature $T_{\mathrm{c}}$, respectively.

Variation of temperature $T_{\mathrm{c} \alpha}$ and $T_{\mathrm{g} \alpha}$ with $\alpha$

The respective values of temperatures $T_{\mathrm{c} \alpha}$ and $T_{\mathrm{g} \alpha}$ in crystallization and glass transition region are calculated at different values of extent of conversion $(\alpha)$. The plots of $\alpha$ versus $T_{\mathrm{c} \alpha}$ and $\alpha$ versus $T_{\mathrm{g} \alpha}$ at four different heating rates are shown in Figs. 5 and 6 . The values of $T_{\mathrm{c} \alpha}$ and $T_{\mathrm{g} \alpha}$ corresponding to $\alpha$ are given in Table 2. From this table, we notice a systematic shift increase in $T$ with increase in heating rate $\beta$.

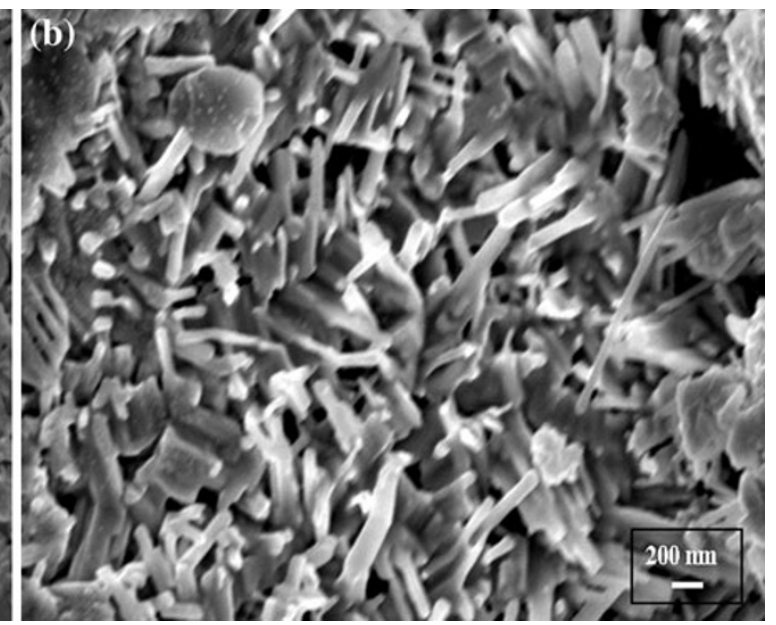

Fig. 2 SEM photographs of as-prepared glassy $\mathrm{Se}_{98} \mathrm{Cd}_{2}$ nanorods at different resolutions 


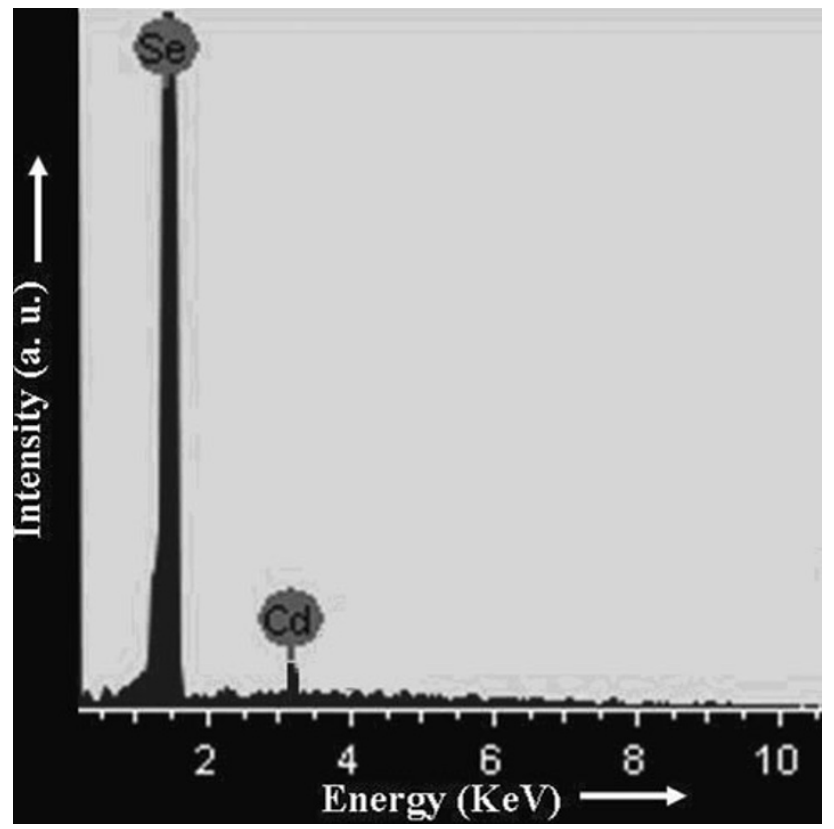

Fig. 3 EDX distribution image of glassy $\mathrm{Se}_{98} \mathrm{Cd}_{2}$ nanorods

Evaluation of activation energy of crystallization and glass transition

The activation energy of crystallization and glass transition are obtained using Kissinger-Akahira-Sunose method (Eq. 5), Flynn-Wall-Ozawa method (Eq. 6), Tang method (Eq. 7) and Straink method (Eq. 8). The plots of $\ln \left(\beta_{i} / T_{\alpha i}^{2}\right)$ versus $1,000 / T_{\mathrm{c} \alpha}$ and $1,000 / T_{\mathrm{g} \alpha}, \ln \left(\beta_{i}\right)$ versus $1,000 / T_{\mathrm{c} \alpha}$ and $1,000 / T_{\mathrm{g} \alpha}, \ln \left(\beta_{i} / T_{\alpha i}^{1.895}\right)$ versus $1,000 / T_{\mathrm{c} \alpha}$ and $1,000 / T_{\mathrm{g} \alpha}$, $\ln \left(\beta_{i} / T_{\alpha i}^{1.92}\right)$ versus $1,000 / T_{\mathrm{c} \alpha}$ and $1,000 / T_{\mathrm{g} \alpha}$. are shown in Figs. 7 and 8. From these figures, one can see that straight

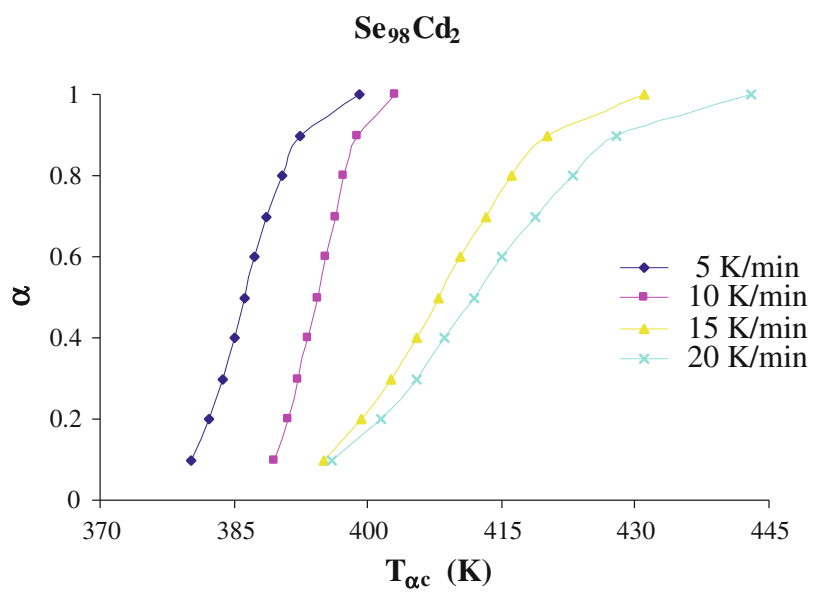

Fig. 5 Plot of $\alpha$ versus temperature $T_{\text {c }}$ for glassy $\mathrm{Se}_{98} \mathrm{Cd}_{2}$ nanorods

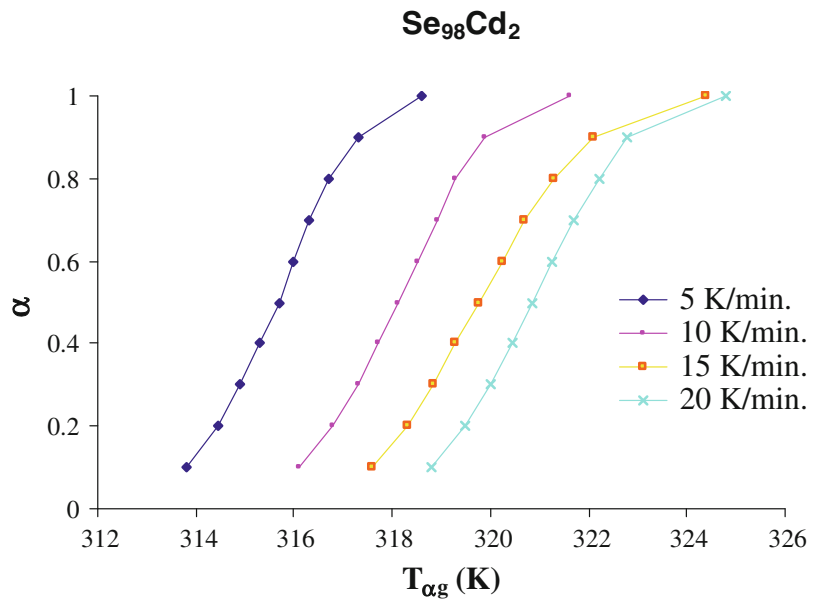

Fig. 6 Plot of $\alpha$ versus temperature $T_{\mathrm{g}}$ for glassy $\mathrm{Se}_{98} \mathrm{Cd}_{2}$ nanorods
Fig. 4 DSC scans at a heating rate $5,10,15$ and $20 \mathrm{~K} / \mathrm{min}$ for glassy $\mathrm{Se}_{98} \mathrm{Cd}_{2}$ nanorods
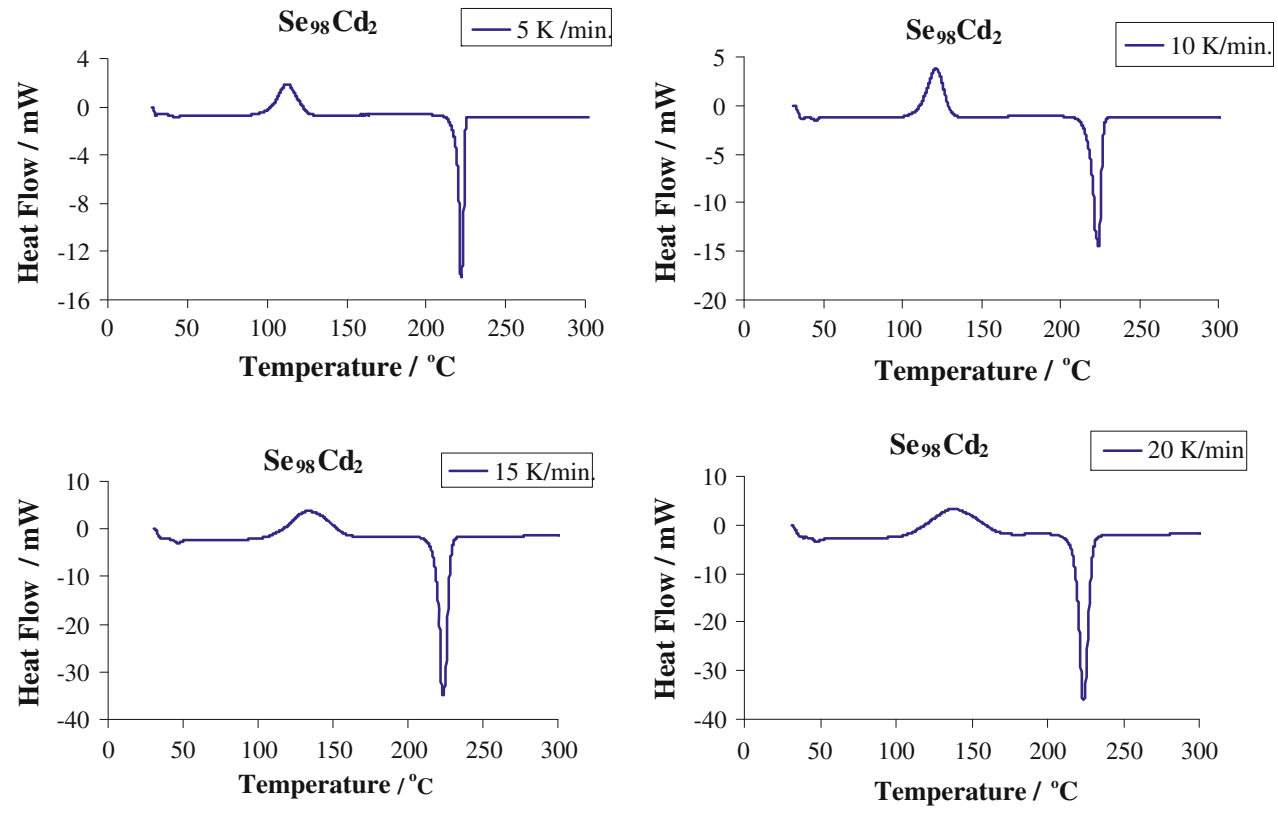
Table 2 Values of temperature in crystallization and glass transition region at different values of extent of conversion $(\alpha)$ and different heating rates

\begin{tabular}{|c|c|c|c|c|c|c|c|c|}
\hline \multirow[t]{2}{*}{ Crystallized fraction $(\alpha)$} & \multicolumn{2}{|l|}{$5 \mathrm{~K} / \mathrm{min}$} & \multicolumn{2}{|c|}{$10 \mathrm{~K} / \mathrm{min}$} & \multicolumn{2}{|c|}{$15 \mathrm{~K} / \mathrm{min}$} & \multicolumn{2}{|c|}{$20 \mathrm{~K} / \mathrm{min}$} \\
\hline & $T_{\alpha \mathrm{c}}(\mathrm{K})$ & $T_{\alpha \mathrm{g}}(\mathrm{K})$ & $T_{\alpha c}(\mathrm{~K})$ & $T_{\alpha \mathrm{g}}(\mathrm{K})$ & $T_{\alpha \mathrm{c}}(\mathrm{K})$ & $T_{\alpha \mathrm{g}}(\mathrm{K})$ & $T_{\alpha \mathrm{c}}(\mathrm{K})$ & $T_{\alpha \mathrm{g}}(\mathrm{K})$ \\
\hline 0.1 & 380.3 & 313.8 & 389.5 & 316.1 & 395.0 & 317.6 & 396.0 & 318.8 \\
\hline 0.2 & 382.3 & 314.4 & 391.1 & 316.8 & 399.4 & 318.3 & 401.5 & 319.5 \\
\hline 0.3 & 383.7 & 314.9 & 392.3 & 317.3 & 402.6 & 318.9 & 405.5 & 320.0 \\
\hline 0.4 & 385.0 & 315.3 & 393.3 & 317.7 & 405.4 & 319.3 & 408.6 & 320.5 \\
\hline 0.5 & 386.1 & 315.7 & 394.3 & 318.1 & 408.0 & 319.8 & 412.0 & 320.9 \\
\hline 0.6 & 387.4 & 316.0 & 395.3 & 318.5 & 410.3 & 320.3 & 415.0 & 321.3 \\
\hline 0.7 & 388.6 & 316.3 & 396.3 & 318.9 & 413.3 & 320.7 & 418.8 & 321.7 \\
\hline 0.8 & 390.4 & 316.7 & 397.4 & 319.3 & 416.2 & 321.3 & 423.0 & 322.2 \\
\hline 0.9 & 392.5 & 317.3 & 398.8 & 319.9 & 420.2 & 322.1 & 428.0 & 322.8 \\
\hline 1.0 & 399.0 & 318.6 & 403.0 & 321.6 & 431.0 & 324.4 & 443.0 & 324.8 \\
\hline
\end{tabular}
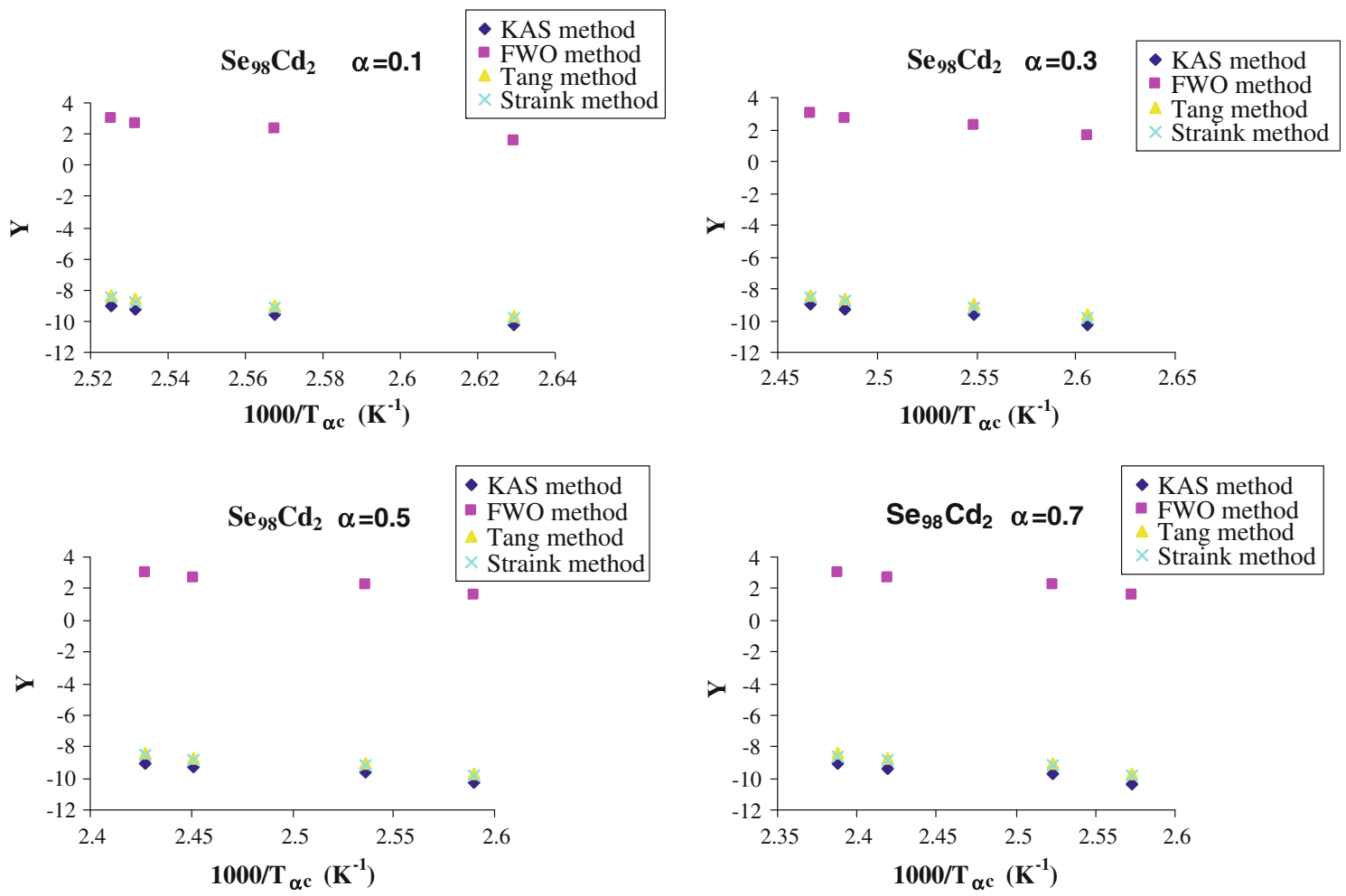

Fig. 7 Plots of $\ln \left(\beta_{i} / T_{\alpha i}^{2}\right)$ versus $10^{3} / T_{\alpha \mathrm{c}}$, ln $(\beta)$ versus $10^{3} / T_{\alpha \mathrm{c}}$, ln $\left(\beta_{i} / T_{\alpha i}^{1.895}\right)$ versus $10^{3} / T_{\alpha \mathrm{c}} \ln$ and $\left(\beta_{i} / T_{\alpha i}^{1.92}\right)$ versus $10^{3} / T_{\alpha \mathrm{c}}$ for glassy $\mathrm{Se}_{98} \mathrm{Cd} \mathrm{g}_{2}$ nanorods

lines of good correlation coefficients are obtained. This confirms the validity of Eqs. (5-7) in the present case. From the slopes of these straight lines, it is possible to derive the value of the activation energy of the crystallization and glass transition. The values of activation energies of crystallization and glass transition calculated from the above-mentioned methods are given in Table 3. From this table, it is clear that the activation energies of crystallization and glass transition for $\mathrm{Se}_{98} \mathrm{Cd}_{2}$ nanorods is not constant, but shows variation in different stages of transformations.

Activation energy with variation of $\alpha$, crystallization and transition temperature

To investigate the variation of activation energies with extent of conversion and temperature, the four isoconversional methods described in Sect. 4 were used. 

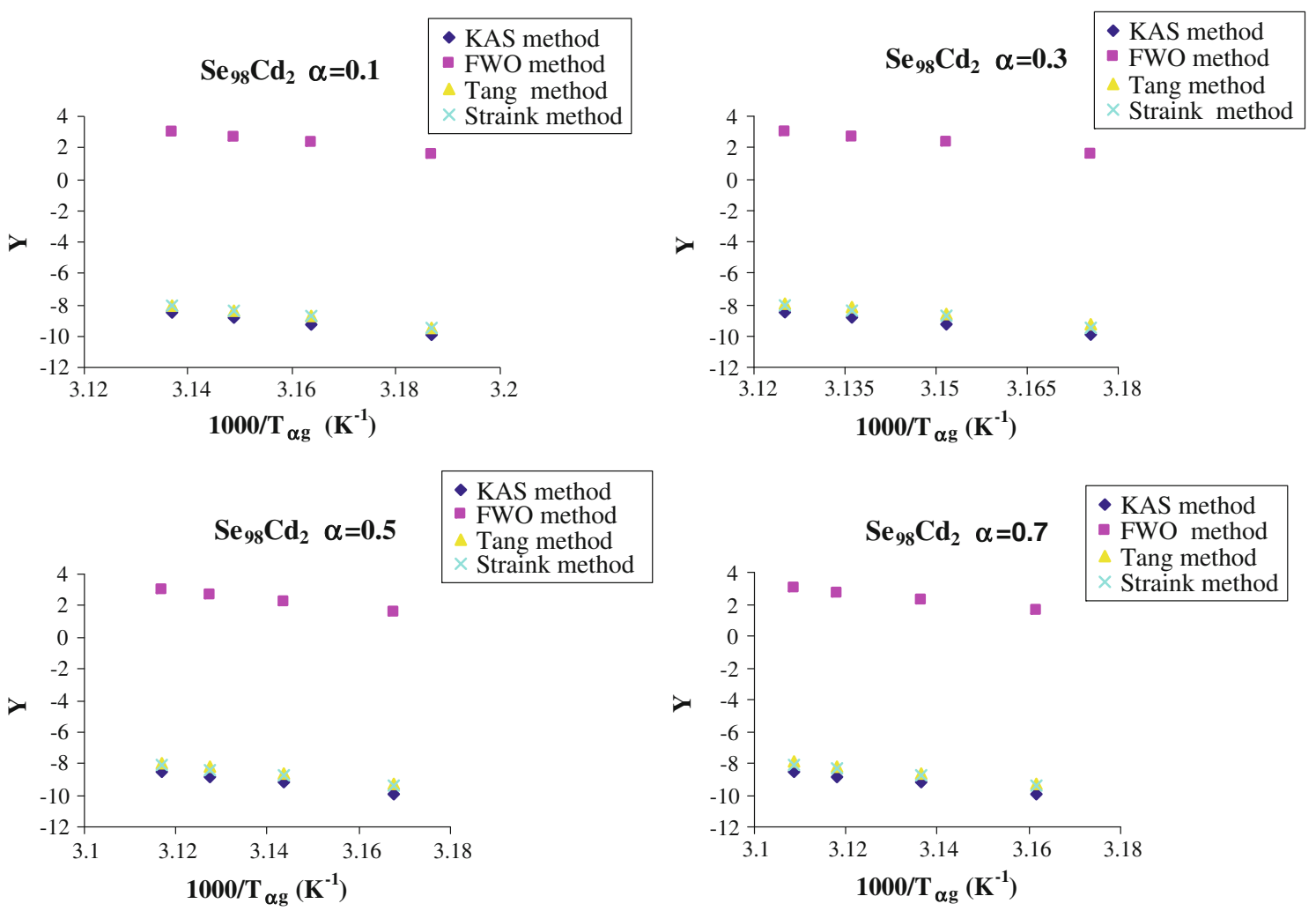

Fig. 8 Plots of $\ln \left(\beta_{i} / T_{\alpha i}^{2}\right)$ versus $10^{3} / T_{\alpha \mathrm{g}}$, ln $(\beta)$ versus $10^{3} / T_{\alpha \mathrm{g}}, \ln \left(\beta_{i} / T_{\alpha i}^{1.895}\right)$ versus $10^{3} / T_{\alpha \mathrm{g}} \ln$ and $\left(\beta_{i} / T_{\alpha i}^{1.92}\right)$ versus $10^{3} / T_{\alpha \mathrm{g}}$ for glassy $\mathrm{Se}_{98} \mathrm{Cd} \mathrm{d}_{2}$ nanorods

Table 3 Variation of activation energies of crystallization and glass transition with extent of conversion $(\alpha)$ determined from different isoconversional methods

\begin{tabular}{|c|c|c|c|c|c|c|c|c|}
\hline \multirow[t]{2}{*}{ Crystallized fraction $(\alpha)$} & \multicolumn{2}{|l|}{ KAS method } & \multicolumn{2}{|l|}{ FWO method } & \multicolumn{2}{|l|}{ Tang method } & \multicolumn{2}{|c|}{ Straink method } \\
\hline & $E_{\alpha \mathrm{c}}(\mathrm{kJ} / \mathrm{mol})$ & $E_{\alpha \mathrm{g}}(\mathrm{kJ} / \mathrm{mol})$ & $E_{\alpha \mathrm{c}}(\mathrm{kJ} / \mathrm{mol})$ & $E_{\alpha \mathrm{g}}(\mathrm{kJ} / \mathrm{mol})$ & $E_{\alpha \mathrm{c}}(\mathrm{kJ} / \mathrm{mol})$ & $E_{\alpha \mathrm{g}}(\mathrm{kJ} / \mathrm{mol})$ & $E_{\alpha \mathrm{c}}(\mathrm{kJ} / \mathrm{mol})$ & $E_{\alpha \mathrm{g}}(\mathrm{kJ} / \mathrm{mol})$ \\
\hline 0.1 & 96.8 & 226.1 & 98.1 & 220 & 97 & 226.1 & 96.9 & 226.1 \\
\hline 0.2 & 80.4 & 224.8 & 82.7 & 218.8 & 80.6 & 224.8 & 80.5 & 224.9 \\
\hline 0.3 & 70.4 & 222.5 & 73.2 & 216.5 & 70.7 & 222.4 & 70.6 & 222.5 \\
\hline 0.4 & 64.1 & 220.5 & 67.2 & 214.6 & 64.4 & 220.4 & 64.3 & 220.5 \\
\hline 0.5 & 58.0 & 220.2 & 61.4 & 214.4 & 58.3 & 220.2 & 58.2 & 220.2 \\
\hline 0.6 & 54.1 & 214.7 & 57.7 & 209.1 & 54.4 & 214.7 & 54.3 & 214.7 \\
\hline 0.7 & 48.7 & 208.4 & 52.7 & 203.2 & 49 & 208.4 & 49.0 & 208.4 \\
\hline 0.8 & 44.6 & 202.9 & 48.8 & 198.0 & 44.9 & 202.9 & 44.8 & 203.0 \\
\hline 0.9 & 40.0 & 199.8 & 44.5 & 195.0 & 40.3 & 199.8 & 40.3 & 199.8 \\
\hline
\end{tabular}

Experimental data of the above-mentioned four methods were used to evaluate the activation energies at different values of $\alpha$ at different heating rates. Figures 9 and 10 show a pronounced variation in the effective activation energy $E_{\alpha}$ as a function of the degree of conversion $\alpha$. As indicated in Figs. 9 and 10, all the methods show a gradual decrease in $E_{\alpha}$ as $\alpha$ increases.
Figure 11 shows the variation in the effective activation energy $E$ as a function of crystallization temperature, $T$, at four different heating rates for each iso-conversional method. The observed decrease in the activation energy with temperature demonstrates that the rate constant of crystallization is in fact determined by the rates of two processes, nucleation and diffusion (Fisher and Turnbull 1949). 


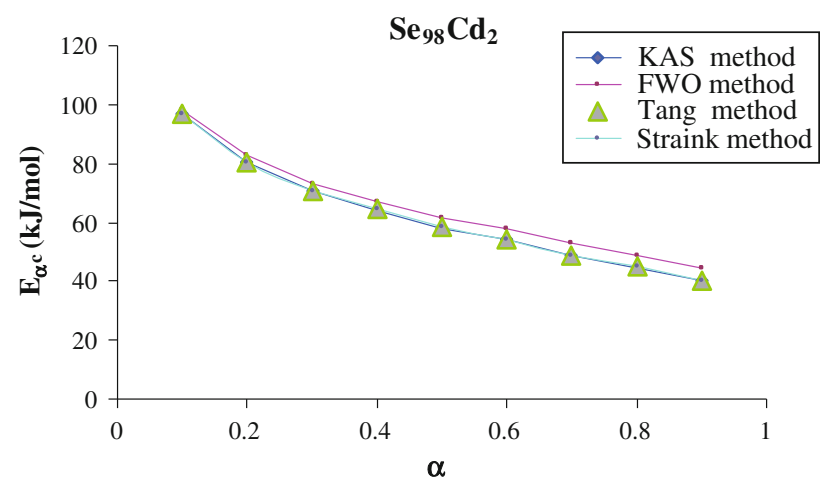

Fig. 9 Plot of activation energy $E_{\alpha c}$ versus conversion fraction $\alpha$, for glassy $\mathrm{Se}_{98} \mathrm{Cd}_{2}$ nanorods

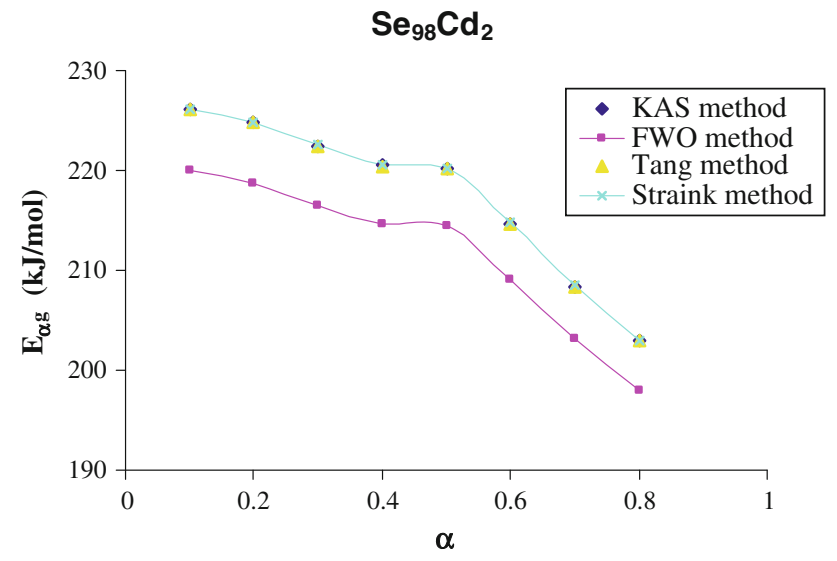

Fig. 10 Plot of activation energy $E_{\alpha \mathrm{g}}$ versus conversion fraction $\alpha$, for glassy $\mathrm{Se}_{98} \mathrm{Cd}_{2}$ nanorods

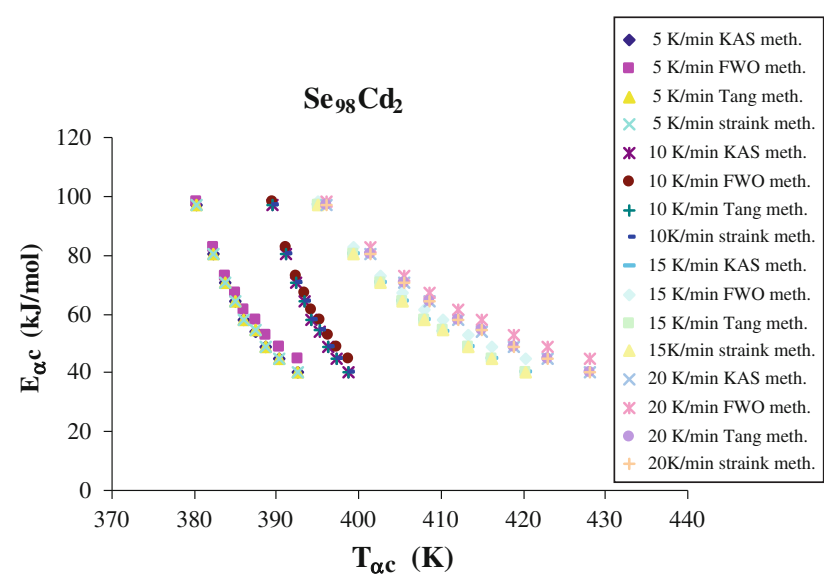

Fig. 11 Plot of $E_{\alpha \mathrm{c}}$ versus $T_{\alpha \mathrm{c}}$ for different methods at different heating rates $(\beta=5,10,15,20 \mathrm{~K} / \mathrm{min})$

Estimation of local Avrami exponent (order parameter) $n$ at different values of $\alpha$

The Avrami exponent is calculated from the following equation (Boutarfaia et al. 2002; Christian 1971):
Table 4 The value of Avrami exponent $n$ for chalcogenide $\mathrm{Se}_{98} \mathrm{Cd}_{2}$ nanorods at different temperatures in crystallization and glass transition regions

\begin{tabular}{llll}
\hline$T(\mathrm{~K})$ & $n_{\mathrm{c}}$ & $T(\mathrm{~K})$ & $n_{\mathrm{g}}$ \\
\hline 91 & 3.7 & 319 & 3.5 \\
93 & 3.3 & 319.4 & 3.1 \\
95 & 3.0 & 320 & 2.7 \\
\hline
\end{tabular}

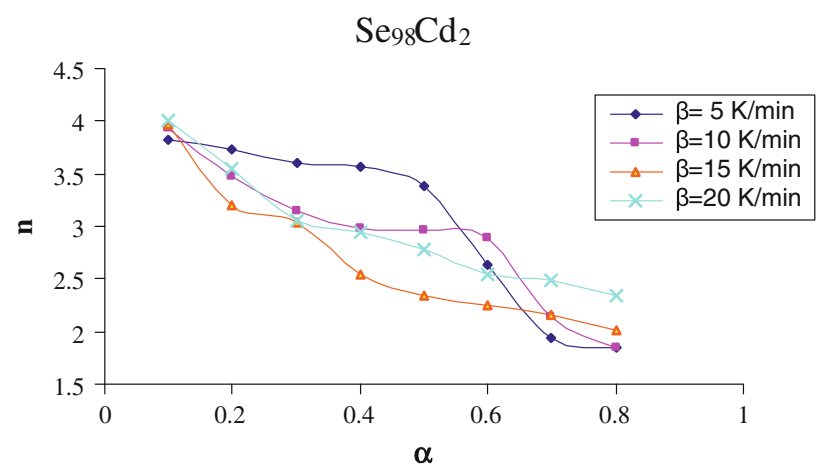

Fig. 12 Plot of local Avrami exponent $n$ versus crystallized fraction $\alpha$, for glassy $\mathrm{Se}_{98} \mathrm{Cd}_{2}$ nanorods

$\ln [-\ln (1-\alpha)]=n \ln \left[K\left(T-T_{o}\right)\right]-n \ln \beta$.

According to above equation, the plot of $\ln [-\ln (1-\alpha)]$ versus $\ln (\beta)$ will be a straight line and the value of Avrami exponent $n$ can be determined from the slopes of such lines. The calculated values of $n$ from the plots of $\ln [-\ln (1-\alpha)]$ versus $\ln (\beta)$ at fixed temperatures in crystallization and glass transition regions are given in Table 4. This table shows that Avrami exponent $n$ decreases with increase in the temperature in crystallization and glass transition regions.

The Avrami exponent can also be calculated from the following equation ( $\mathrm{Lu}$ et al. 2005):

$n(\alpha)=-\frac{R}{E(\alpha)} \frac{\partial \ln [-\ln (1-\alpha)]}{\partial\left(\frac{1}{T}\right)}$.

The calculated values of the Avrami exponent $n$ for different heating rates are plotted as a function of $\alpha$ (See Fig. 12). The Avrami exponent $n$ shows strong dependence on $\alpha$. This is consistent with a reaction dominated by continuous nucleation and interface-controlled growth. It is well known that crystallization of chalcogenide glasses is associated with nucleation and growth process and the extent of crystallization $\alpha$ increases with increase in temperature. In other words, it tends to its maximum value 1 . The decreasing trend of $n$, therefore, shows the decrease in the nucleation rate due to nucleation saturation. 


\section{Conclusions}

We have synthesized high yield of $\mathrm{Se}_{98} \mathrm{Cd}_{2}$ nanorods using melt quenching technique. From SEM photographs, it is found that the sample contains high yield of nanorods and their diameters are of the order of several hundred nanometers. XRD pattern of this material suggests that these nanorods are amorphous in nature. $\mathrm{Se}, \mathrm{Cd}$ and $\mathrm{CdSe}$ hexagonal phases are observed in XRD pattern of the annealed sample. Using the iso-conversional methods, the glass transition and crystallization behavior of the present glass has been studied by differential scanning calorimetry. We have employed four approaches to study the variation of activation energies of glass transition and crystallization with the extent of conversion. The order parameter $n$ is found to decrease with increase in the temperature and degree of conversion.

Acknowledgments One of us, NM, is thankful to the Council of Scientific and Industrial Research (CSIR), New Delhi, India, for providing financial assistance under the Major Research Project [Scheme number: (03(1177)/10].

Open Access This article is distributed under the terms of the Creative Commons Attribution License which permits any use, distribution, and reproduction in any medium, provided the original author(s) and the source are credited.

\section{References}

Abu-Sehly AA (2009) Variation of the activation energy of crystallization in $\mathrm{Se}_{81.5} \mathrm{Te}_{16} \mathrm{Sb}_{2.5}$ chalcogenide glass: Isoconversional analysis. Thermochim Acta 485:14-19

Abu-Sehly AA (2011) Kinetics of the glass transition in As22S78 chalcogenide glass: activation energy and fragility index. Mater Chem Phys 125:672-677

Akahira T, Sunose T (1971) Trans joint convention of four electrical institutes. Res Rep Chiba Inst Tech 16:22-31

Boutarfaia A, Legouera M, Poulain M (2002) Nucleation and crystallization in floroindate glasses. Int J Therm Sci 4:157-162

Christian JW (1971) The theory of transformation in metals and alloys. Part 1, 2nd edn. Pergamon, New York, p 437

Doyle CD (1961) Kinetic analysis of thermo gravimetric data. J Appl Polym Sci 5:285-292

Doyle CD (1965) Series approximations to the equation of thermogravimetric data. Nature 207:290-291

Felice S, Saunders AE, Korgel BA (2005) General shape control of colloidal CdS, CdSe, CdTe quantum rods and quantum rod heterostructure. J Phys Chem B 109:8538-8542

Fisher JC, Turnbull D (1949) Rate of nucleation in condensed systems. J Chem Phys 17:71-73

Flynn JH, Wall LA (1966) General treatment of thermogravimetry of polymers. J Res Natl Bur Stand A 70:487-490

Friedman H (1964) Kinetics of thermal-degradation of char-forming plastics from thermogravimetry: application to a phenolic plastic. J Polym Sci C 6:183-195

Geim AK, Novoselov KS (2007) The rise of grapheme. Nat Mater 6:183-191
Hu J, Odoc TW, Lieber CM (1999) Chemistry and physics in one dimention: synthesis and properties of nanowires and nanotubes. Acc Chem Res 32:435-445

Jorio A, Dresselhaus G, Dresselhaus MS (2008) Carbon nano tubes. Top appl Phys 111:673-709

Jun Y, Lee S, Kang N, Cheon J (2001) Controlled synthesis of multiarmed CdS nanorod architectures mono-surfactant system. J Am Chem Soc 123:5150-5151

Jung Y, Agarwal R, Yang CY, Agarwal R (2011) Chalcogenide phase-change memory nanotubes for lower writing current operation. Nano Technol 22:254012

Khan ZH, Husain M (2009) Electrical and optical properties of thin film of a-Se $\mathrm{Se}_{70} \mathrm{Te}_{30}$ nanorods. J Alloy Compd 486:774-779

Khan ZH, Khan SA, Salah N, Habib S, Abdullah El-Hamidy SM, AlGhamdi AA (2010a) Effect of composition on electrical and optical properties of thin films of amorphous $\mathrm{Ga}_{x} \mathrm{Se}_{100-x}$ nanorods. Nanoscale Res Lett 5:1512-1517

Khan SA, Al-Agel FA, Faidah AS, Yaghmour SJ, Al-Ghamdi AA (2010b) Characterization of $\mathrm{Se}_{88} \mathrm{Te}_{12}$ nano structured chalogenide prepa red by ball milling. Mat Lett 64:1391-1393

Khan ZH, Khan SA, Salah N, Habib SS, Al-Ghamdi AA (2011) Electrical transport properties of thin film of a-Se ${ }_{87} \mathrm{Te}_{13}$ nanorods. J Exp Nanosci 6(4):337-348

Kissinger HE (1956) Variation of peak temperature with heating rate in temperature differential thermal analysis. J Re Natl Bur Stand $57: 217-221$

Kissinger HE (1957) Reaction kinetics in differential thermal analysis. Anal Chem 29:1702-1706

Kotkata MF, Mansour SA (2010) Crystallization process analysis for $\mathrm{Se}_{0.95} \mathrm{In}_{0.05}$ and $\mathrm{Se}_{0.90} \mathrm{In}_{0.10}$ chalcogenide glasses using the contemporary isoconversional models. J Therm Anal Cal 103: 957-965

Li LS, Hu J, Yang W, Alivisatos AP (2001) Band gap variation of size and shape controlled colloidal CdSe quantum dot. Nano Lett $1: 349-351$

Lu W, Yan B, Huang W (2005) Complex primary crystallization kinetics of amorphous finemet alloy. J Non Cryst Solids 35: $3320-3324$

Mehta RJ, Karthik C, Singh B, Teki R, Borca-Tasciuc T, Ramnath G (2010) Seebeck tuning in chalcogenide nanoplate assemblies by nanoscale heterostructuring. ACS Nano 4:5055-5060

Morales AM, Lieber CM (1998) A laser ablation method for the synthesis of crystalline semiconducting nanowires. Science 297:208-211

Ozawa T (1965) A new method of analyzing thermo gravimetric data. Bull Chem Soc Jpn 38:186-188

Ozawa T (1971) Kinetics of non-isothermal crystallization. Polymer 12:150-158

Purnima T, Ruberu Vela J (2011) Expanding the one-dimensional CdS-CdSe composition landscape: axially anisotropic CdS1xSex norods. ACS Nano 5:5775

Sava F, Simandan D (2010) Carbon-chalcogenide nanotube confuguration. Proc Romanian Acad 11:232-235

Starink MJ (2003) The determination of activation energy from linear heating rate experiments: a comparison of the accuracy of isoconversion methods. Thermochim Acta 404:163-176

Starink MJ (2007) Comments on precipitation kinetics of $\mathrm{Al}-1.12 \mathrm{Mg}$ $\mathrm{Si}-0.35 \mathrm{Si}$ and $\mathrm{Al}-1.07 \mathrm{Mg} \mathrm{Si-} 0.33 \mathrm{Cu}$ alloys. J Alloy Compd 443:L4-L6

Tripathi K, Bahisti AA, Khan MAM, Husain M, Zulfequar M (2009) Optical properties of selenium-tellurium nanostructured thin film grown by thermal evaporation. Phys B 404:2134-2137

Vyazovkin S (1996) A unified approach to kinetic processing of nonisothermal data. Int J Chem Kinet 28(2):95-101

Vyazovkin S (2000) Computational aspects of kinetic analysis. Thermochim Acta 355:155-163 
Vyazovkin S, Sbirrazzuoli N (2003) Estimating the activation energy for non-isothermal crystallization of polymer melts. Thermochim Acta 72:681-686

Vyazovkin S, Sbirrazzuoli N (2006) Isoconversional kinetic analysis of thermally stimulated processes in polymers. Macromol Rapid Commun 27:1515-1532

Vyazovkin S, Sbirrozzuoli N (1996) Mechanism and kinetics of epoxy- amine cure studied by differential scanning calorimetry. Macromolecules 29:1867-1873
Wallace PR (1947) Band theory of graphite. Phys Rev 71:622-634

Wanjun T, Donghua C (2005) An integral method to determine variation in activation energy with extent of conversion. Thermochim Acta 443:72-76

Yu H, Liu Y, Brock SL (2009) Tuning the optical band gap of quantum dot assemblies by varing network density. ACS Nano 3:2000-2008 